\title{
Altered localisation of the copper efflux transporters ATP7A and ATP7B associated with cisplatin resistance in human ovarian
} carcinoma cells

\author{
Ganna V Kalayda*1, Christina H Wagner ${ }^{1}$, Irina Buß1 ${ }^{1}$, Jan Reedijk ${ }^{2}$ and \\ Ulrich Jaehde ${ }^{1}$
}

Address: ${ }^{1}$ Department of Clinical Pharmacy, Institute of Pharmacy, University of Bonn, An der Immenburg 4, 53121 Bonn, Germany and ${ }^{2}$ Leiden Institute of Chemistry, Leiden University, P.O. Box 9502, 2300 RA Leiden, The Netherlands

Email: Ganna V Kalayda* - akalayda@uni-bonn.de; Christina H Wagner - chwagner@uni-bonn.de; Irina Buß - i.buss@uni-bonn.de; Jan Reedijk - reedijk@chem.leidenuniv.nl; Ulrich Jaehde - u.jaehde@uni-bonn.de

* Corresponding author

Published: 19 June 2008

BMC Cancer 2008, 8:175 doi:10.1186/147|-2407-8-175
Received: I February 2008

Accepted: 19 June 2008

This article is available from: http://www.biomedcentral.com/I47I-2407/8/I75

(c) 2008 Kalayda et al; licensee BioMed Central Ltd.

This is an Open Access article distributed under the terms of the Creative Commons Attribution License (http://creativecommons.org/licenses/by/2.0), which permits unrestricted use, distribution, and reproduction in any medium, provided the original work is properly cited.

\begin{abstract}
Background: Copper homeostasis proteins ATP7A and ATP7B are assumed to be involved in the intracellular transport of cisplatin. The aim of the present study was to assess the relevance of sub cellular localisation of these transporters for acquired cisplatin resistance in vitro. For this purpose, localisation of ATP7A and ATP7B in A2780 human ovarian carcinoma cells and their cisplatinresistant variant, $A 2780$ cis, was investigated.
\end{abstract}

Methods: Sub cellular localisation of ATP7A and ATP7B in sensitive and resistant cells was investigated using confocal fluorescence microscopy after immunohistochemical staining. Colocalisation experiments with a cisplatin analogue modified with a carboxyfluorescein-diacetate residue were performed. Cytotoxicity of the fluorescent cisplatin analogue in A2780 and A2780cis cells was determined using an MTT-based assay. The significance of differences was analysed using Student's $t$ test or Mann-Whitney test as appropriate, $\mathrm{P}$ values of $<0.05$ were considered significant.

Results: In the sensitive cells, both transporters are mainly localised in the trans-Golgi network, whereas they are sequestrated in more peripherally located vesicles in the resistant cells. Altered localisation of ATP7A and ATP7B in A2780cis cells is likely to be a consequence of major abnormalities in intracellular protein trafficking related to a reduced lysosomal compartment in this cell line. Changes in sub cellular localisation of ATP7A and ATP7B may facilitate sequestration of cisplatin in the vesicular structures of A2780cis cells, which may prevent drug binding to genomic DNA and thereby contribute to cisplatin resistance.

Conclusion: Our results indicate that alterations in sub cellular localisation of transport proteins may contribute to cisplatin resistance in vitro. Investigation of intracellular protein localisation in primary tumour cell cultures and tumour tissues may help to develop markers of clinically relevant cisplatin resistance. Detection of resistant tumours in patients may in turn enable individualization of the chemotherapy in the early stage of treatment. 


\section{Background}

Despite the success of cisplatin-based anticancer chemotherapy, its application is limited because in most cases, tumours develop resistance after repeated administrations of the drug. Acquired cisplatin resistance is a net result of multiple pathways, which often act simultaneously in a given cell $[1,2]$. Furthermore, primary mechanisms that determine a resistant phenotype vary significantly between different cancer cell lines [3], and also defects in drug transport appear to play a major role in development of resistance $[4,5]$. The mechanisms mediating uptake, intracellular transport and efflux of cisplatin remain largely obscure [6]. In the past decade, a number of studies have provided evidence that the copper homeostasis proteins ATP7A and ATP7B are involved [7-10]. These Ptype ATPases have been suggested to either sequester cisplatin in vesicular structures or to mediate efflux of the drug $[11,12]$. Increased expression of ATP7A and ATP7B has been associated with acquired resistance to cisplatin in cancer cell line models and in clinical samples $[7,8,11,13,14]$.

Under basal conditions, when extracellular copper concentrations are low, ATP7A and ATP7B are localised in the trans-Golgi network. Exposure to increased copper levels results in re-localisation of ATP7A to the plasma membrane and of ATP7B to intracellular vesicular compartments. For both proteins, this re-localisation is reversible once copper has been removed from the culture medium. Copper-regulated trafficking of ATP7A and ATP7B is believed to be important for maintaining copper homeostasis [15-17]. The effect of cisplatin on sub cellular localisation of these copper transporters was studied in cell lines molecularly engineered to express either ATP7A or ATP7B. In these cell lines, which exhibited a biologically relevant degree of resistance, both transporters were found to localise in the trans-Golgi network in the absence of cisplatin. Cisplatin exposure triggered re-localisation of ATP7B (and not ATP7A) from the trans-Golgi to more peripherally located vesicles $[10,18,19]$. These findings suggest that ATP7B mediates cisplatin efflux, while ATP7A is rather involved in the intracellular sequestration of the drug [12].

The issue of sub cellular localisation of ATP7A and ATP7B in cell lines, selected for cisplatin resistance, has not yet been addressed. Recently, we characterised an A2780/ A2780cis cisplatin-sensitive/resistant human ovarian carcinoma cell line pair with respect to cisplatin sensitivity, drug accumulation and efflux, DNA platination, as well as expression of copper homeostasis proteins [20]. In the present study, we have investigated localisation of ATP7A and ATP7B in these cell lines and found that both proteins have a different localisation pattern in the resistant cells as compared to the sensitive cells. Here we discuss the factors that likely account for changes in sub cellular localisation of ATP7A and ATP7B and consider relevance of altered protein localisation for decreased cisplatin sensitivity in the resistant cell line.

\section{Methods \\ Materials}

Bafilomycin $\mathrm{A}_{1}$, MTT (MTT = 3-(4,5-dimethylthiazol-2yl)-2,5-diphenyl-2H-tetrazolium bromide), Triton X-100, bovine serum albumin (BSA), ribonuclease A (RNAse A), fluorescein isothiocyanate-dextran (FITC-dextran, $\mathrm{M}=$ 70000), GelMount ${ }^{\mathrm{TM}}$ mounting medium and cis-diamminedichloridoplatinum(II) (cisplatin) were obtained from Sigma (Steinheim, Germany). LysoTracker ${ }^{\mathrm{TM}}$ Red DND-99, Hoechst 33342, ALEXA Fluor ${ }^{\mathrm{TM}}$ 488- and ALEXA Fluor $^{\mathrm{TM}}$ 594-conjugated chicken anti-goat antibodies, NBD-C ${ }_{6}$-ceramide (6-((N-(7-nitrobenz-2-oxa-1,3-diazol4-yl)amino)hexanoyl)-sphingosine) complexed to BSA, propidium iodide were ordered form Invitrogen (Karlsruhe, Germany). Goat antibodies to ATP7A and ATP7B were from Santa Cruz Biotechnology, Inc. (Santa Cruz, CA, USA). All solvents were reagent grade and were used as purchased. [ $\{1-([5-($ and-6)-carboxyfluorescein diacetate]aminomethyl)-1,2-ethylenediamine $\}$ dichloridoplatinum(II)] (CFDA-Pt) was synthesised according to the previously published method [21]. Briefly, the protection Boc (t-butyloxycarbonyl) group of [ $\{1-(t-b u t y l o x y c a r b o-$ nyl)-aminomethyl)-1,2-ethylenediamine $\}$ dichloridoplatinum(II)] was removed in $0.1 \mathrm{M} \mathrm{HCl}$ at $60^{\circ} \mathrm{C}$ overnight. The resulting solution was neutralised to $\mathrm{pH} 7.5$ with $2 \mathrm{M}$ $\mathrm{NaOH}$ and allowed to react with 0.9 eq 5-(and-6)-carboxyfluorescein diacetate, succinimidyl ester (Invitrogen, Karlsruhe, Germany), for $15 \mathrm{~min}$ at $0^{\circ} \mathrm{C}$ and subsequently for $30 \mathrm{~min}$ at room temperature in order to obtain the desired compound. The resulting precipitate was centrifuged off and successively washed with water, ethanol end ether. The product was characterised by ${ }^{1} \mathrm{H}$ and ${ }^{195} \mathrm{Pt}$ NMR spectroscopy and mass spectrometry.

\section{Cell lines and growth conditions}

A2780 and A2780cis (cisplatin-resistant) human ovarian carcinoma cell lines were grown as monolayers in RPMI1640 medium supplemented with $10 \%$ foetal calf serum, L-glutamine, penicillin and streptomycin (Sigma, Steinheim, Germany) in a humidified 5\% $\mathrm{CO}_{2}, 95 \%$ air atmosphere.

\section{Drug sensitivity in the $\mathbf{A 2 7 8 0}$ and $\mathbf{A 2 7 8 0}$ cis cell lines}

Cytotoxicity of cisplatin, CFDA-Pt and bafilomycin $A_{1}$ in A2780 and A2780cis cells was evaluated using an MTTbased assay [22]. After trypsinisation, the cells were divided in 96-well plates at concentrations of $10^{4}$ cells/ well in $100 \mu \mathrm{l}$ growth medium. The cells were allowed to attach overnight. Then, medium was removed and stock solutions of cisplatin in millipore water $(2 \mathrm{mg} / \mathrm{ml})$, 
CFDA-Pt in dimethylformamide $(50 \mathrm{mM})$ and bafilomycin $A_{1}$ in dimethylsulfoxide $(100 \mathrm{mM})$ were diluted in medium. Six subsequent dilutions each were added to the cells in quadruplicate $(100 \mu \mathrm{l} /$ well $)$. Some control wells contained $0.5 \%$ dimethylformamide, which corresponded to the highest solvent concentration in the dilutions of CFDA-Pt. After $72 \mathrm{~h}$ of incubation, $50 \mu \mathrm{l}$ of a 5 $\mathrm{mg} / \mathrm{ml}$ MTT solution in phosphate buffered saline (PBS) was added to each well, and the cells were incubated at $37^{\circ} \mathrm{C}$ for about $90 \mathrm{~min}$. Subsequently, medium was discarded and $100 \mu \mathrm{l}$ of dimethylsulfoxide was added to each well, yielding purple solutions. The optical density was measured at $590 \mathrm{~nm}$ using a Multiskan ${ }^{\mathrm{TM}}$ microplate reader (ThermoLabsystems, Dreieich, Germany). The results were analysed and the $\mathrm{pEC}_{50}$ values $\left(\mathrm{pEC}_{50}=-\log \right.$ $\mathrm{EC}_{50}, \mathrm{EC}_{50}$ is the drug concentration that produces $50 \%$ of the maximum possible response) were determined with the GraphPad Prism ${ }^{\mathrm{TM}}$ analysis software package (GraphPad Software, San Diego, USA) using non-linear regression (sigmoidal dose response, variable slope).

\section{Lysosomal and endosomal acidification}

Acidification of lysosomal and endosomal compartments in A2780 and A2780cis cells was compared using FITCdextran. Labelling of endosomes and lysosomes with FITC-dextran was performed according to the literature procedures [23,24]. Briefly, A2780 and A2780cis cells were divided in a 96-well plate at concentrations of $10^{5}$ cells/well in $100 \mu \mathrm{l}$ growth medium. The cells were allowed to attach for $6 \mathrm{~h}$. Subsequently, the medium was discarded and FITC-dextran $(5 \mathrm{mg} / \mathrm{ml})$ dissolved in serum-free medium was added to the cells. To label endosomes the cells were incubated with FITC-dextran for 5 min, to label lysosomes they were incubated with FITCdextran for 30 min followed by washing with serum-free medium and subsequent incubation with this medium for $90 \mathrm{~min}$. After labelling of endosomes or lysosomes, the cells were washed with serum-free medium, and complete medium was added to the cells. Fluorescence intensity was measured using a Polarstar-Galaxy ${ }^{\mathrm{TM}}$ microtitre plate reader (BMG-Lab-Technologies, Offenburg, Germany).

\section{Flow cytometry}

$10^{6}$ cells (A2780 or A2780cis) were incubated with LysoTracker $^{\mathrm{TM}}$ Red DND-99 (1 $\left.\mu \mathrm{M}\right)$ in RPMI-1640 for $30 \mathrm{~min}$, centrifuged, washed with the medium, and re-suspended in normal growth medium. Then fluorescence was measured using a FACSort ${ }^{\mathrm{TM}}$ flow cytometer (BD Biosciences).

\section{Immunohistochemical staining}

Immunohistochemical staining was done one day after seeding cells on cover slips. In some experiments, cells were pre-treated with either $5 \mu \mathrm{M}$ cisplatin, $5 \mu \mathrm{M}$ CFDAPt or $200 \mathrm{nM}$ bafilomycin $\mathrm{A}_{1}$ for $1 \mathrm{~h}$. Lysosomes were labelled in RPMI-1640 containing $1 \mu \mathrm{g} / \mathrm{ml}$ LysoTracker ${ }^{\mathrm{TM}}$ Red DND-99 at $37^{\circ} \mathrm{C}$ for $1 \mathrm{~h}$. In some experiments, nuclei were stained with $5 \mu \mathrm{M}$ Hoechst 33342 at $37^{\circ} \mathrm{C}$ for $1 \mathrm{~h}$. After three rinses with PBS, cells were fixed with 3.7\% formaldehyde in PBS for 15 min at room temperature. After fixation, cells were washed three times with PBS and permeablilised with $0.5 \%$ Triton X-100 in PBS for $30 \mathrm{~min}$. Labelling of the trans-Golgi network was performed with $5 \mu \mathrm{M} \mathrm{NBD}-\mathrm{C}_{6}$-ceramide complexed to BSA at $37^{\circ} \mathrm{C}$ for 30 min. Cells were then rinsed with PBS, blocked for $1 \mathrm{~h}$ in PBS containing 1\% BSA followed by incubation for 90 min at $37^{\circ} \mathrm{C}$ with a primary antibody against the respective transport protein (ATP7A or ATP7B). Subsequently, cells were washed with PBS and incubated for $90 \mathrm{~min}$ at $37^{\circ} \mathrm{C}$ with the secondary ALEXA Fluor ${ }^{\mathrm{TM}} 488$ - or ALEXA Fluor $^{\mathrm{TM}}$ 594-conjugated antibody. Antibody solutions were diluted in PBS containing 1\% BSA. To stain the nucleus with propidium iodide in some samples, cells were treated with RNAse A $(100 \mu \mathrm{g} / \mathrm{ml}$ in PBS $)$ for $30 \mathrm{~min}$ at $37^{\circ} \mathrm{C}$, washed with PBS and incubated with $5 \mu \mathrm{M}$ propidium iodide in $\mathrm{PBS}$ for $15 \mathrm{~min}$ at $37^{\circ} \mathrm{C}$. After the final washing steps, the cells were gradually dehydrated in an ethanol series of $70 \%, 90 \%, 100 \%$, for 1 min each. The cover slips were mounted in GelMount ${ }^{\mathrm{Tm}}$ medium for microscopic observations. Images showing staining of lysosomes with LysoTracker ${ }^{\mathrm{TM}}$ Red in both cell types are representative each of five images, which were recorded using an Olympus U-TBI90 confocal system at Laboratory of Molecular Immunology, LIMES Institute, University of Bonn. Other images in this article are each representative of five images taken using a Leica TCS SP2 confocal system at Laboratory for Molecular Developmental Biology, LIMES Institute, University of Bonn. Each fluorochrome was scanned individually and each image included $5-20$ cells. The number of cells showing a certain pattern (e.g. TGN localised protein) was counted in every image and expressed as a percentage of all cells in the image. Then the median percentage values from different images were calculated.

\section{Statistics}

The significance of differences was analysed using Student's $t$ test or Mann-Whitney test as appropriate, $\mathrm{p}$ values of $<0.05$ were considered significant.

\section{Results}

\section{Sub cellular localisation of ATP7A and ATP7B}

In A2780 cell line, the fluorescent signals corresponding to ATP7A and ATP7B are limited to the perinuclear regions of the cells (Figure 1). Previously published studies in other cell systems reported localisation of both proteins in the trans-Golgi network [16-19,25,26]. However, in cisplatin-resistant A2780cis cells the proteins are distributed away from the perinuclear region to more peripherally located vesicles in the cytosol (Figure 1). The 

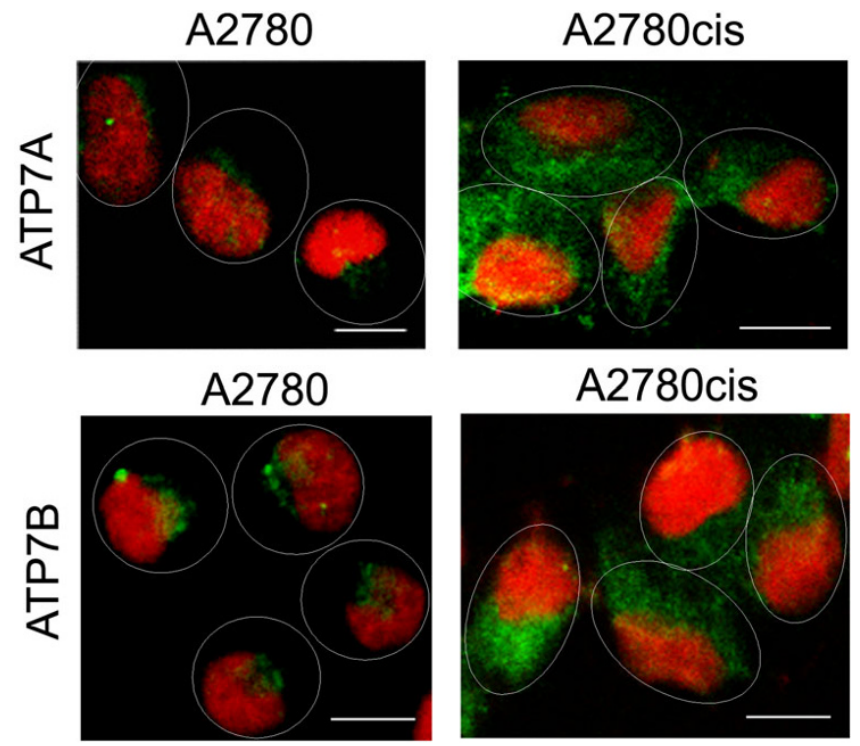

Figure I

Sub cellular localisation of ATP7A and ATP7B in A2780 and A2780cis cells. Immunofluorescence localisation of ATP7A and ATP7B (both green) in A2780 and A2780cis cells. Cell nuclei were stained with propidium iodide (red). Ovals indicate cell periphery. Scale bar, $10 \mu \mathrm{m}$.

percentage of sensitive and resistant cells showing dispersed localisation of the proteins is given in Table 1 . We also distinguished between dividing (located next to each other) and non-dividing cells since dividing cells are more likely to show dispersed protein localisation. In order to confirm localisation of ATP7A and ATP7B in the transGolgi network of the sensitive cells, and re-localisation of the transporters in the resistant cells, co-localisation experiments using $\mathrm{NBD}_{-} \mathrm{C}_{6}$-ceramide, a fluorescent marker for the Golgi complex, were performed. Images presented in Figure 2 show substantial co-localisation of both proteins with $\mathrm{NBD}-\mathrm{C}_{6}$-ceramide in A2780 cells and a negligible degree of co-localisation in A2780cis cells. The percentage of cisplatin-sensitive and -resistant cells that show co-localisation of the proteins with the Golgi marker is presented in Table 2.

In order to investigate the effect of drug exposure on protein localisation, A2780 cells were treated with $5 \mu \mathrm{M}$ cisplatin for $1 \mathrm{~h}$. Cisplatin triggered redistribution of ATP7A and ATP7B from the perinuclear region to more peripherally located sites in the cytosol. Interestingly, localisation of both proteins in the area close to the nucleus was fully restored within $1 \mathrm{~h}$ after removal of the drug from the culture medium (Figure 3). The percentage of cells, which show dispersed localisation of the transporters in A2780 cells after cisplatin treatment and after subsequent incubation with the drug-free medium was determined, and the values are presented in Table 3. However, since no inhibitors of protein synthesis were used, return of ATP7A and ATP7B to localisation in the trans-Golgi network may or may not reflect a retrograde traffic of the proteins.

Rapid cisplatin-induced re-localisation of ATP7A and ATP7B towards the cell periphery and quick return of the proteins back to the trans-Golgi network suggests that cisplatin-controlled trafficking of the transporters may indicate an efflux pathway of the drug. Cisplatin binding to the protein may result in protein redistribution to (secretory) vesicles, followed by drug excretion and re-localisation of the protein back to the trans-Golgi network. Cisplatin exposure had no effect on protein localisation in the resistant cell line (images not shown).

\section{Constitutive recycling of ATP7A and ATP7B in A2780 cells}

Some cellular proteins (e.g. furin and TGN38) are known to continuously recycle between the trans-Golgi network and the plasma membrane and to be localised in the transGolgi by a process of continuous retrieval from the cell surface $[27,28]$. Drugs which inhibit endosomal recycling lead to sequestration of these proteins in vesicles of the endosomal pathway [29,30]. In order to investigate, whether ATP7A and ATP7B continuously recycle between the trans-Golgi network and the cell periphery, the effect of bafilomycin $\mathrm{A}_{1}$, a drug that blocks endosomal retrieval by inhibiting the vacuolar $\mathrm{H}^{+}$-ATPase [31], on intracellular localisation of ATP7A and ATP7B in the sensitive A2780 cells was studied. As shown in Figure 4, exposure of A2780 cells to $200 \mathrm{nM}$ bafilomycin $\mathrm{A}_{1}$ for $1 \mathrm{~h}$ triggered redistribution of the proteins from the trans-Golgi to more peripherally located vesicular structures. This was the case in $77.5 \%$ cells for ATP7A and in $72.7 \%$ cells for ATP7B (median percentage is given). These results provide evidence of continuous recycling of ATP7A and ATP7B between the Golgi apparatus and cell periphery in the sensitive cells. Therefore, in the sensitive cell line the proteins are likely to localise in the trans-Golgi network by a process of continuous retrieval from the peripherally located vesicles.

In order to investigate whether arrest of endosomal recycling can render A2780 cells resistant to cisplatin, we intended to assess the influence of bafilomycin $\mathrm{A}_{1}$ on cisplatin sensitivity. Unfortunately, it was not possible because of the adverse effect of bafilomycin $\mathrm{A}_{1}$ treatment on cell viability. The $\mathrm{EC}_{50}$ values for bafilomycin $\mathrm{A}_{1}$ were determined as $8.5 \mathrm{nM}\left(\mathrm{pEC}_{50}=8.07 \pm 0.14\right.$, mean $\left.\pm \mathrm{SE}\right)$ in the A2780 cell line and $12 \mathrm{nM}\left(\mathrm{pEC}_{50}=7.92 \pm 0.1\right.$, mean $\pm \mathrm{SE})$ in the A2780cis cell line. However, the concentrations of the drug, which do not affect cell viability $(<10$ $\mathrm{nM}$ ), are not high enough to block the activity of a vacuolar $\mathrm{H}^{+}$-ATPase [32]. 


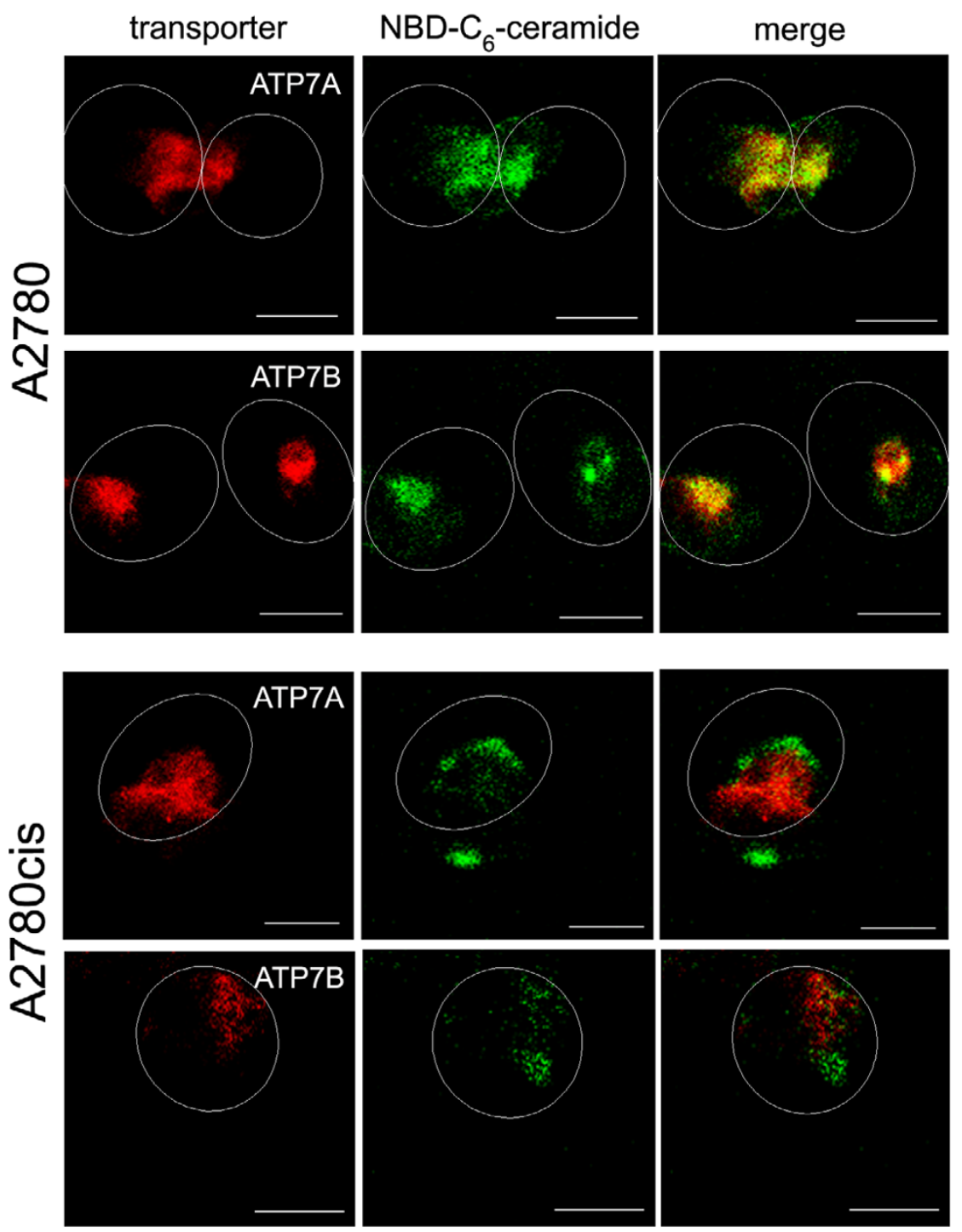

Figure 2

Co-localisation of ATP7A and ATP7B with a trans-Golgi network marker. Co-localisation of markers for ATP7A and ATP7B (both red) with NBD-C 6 -ceramide (green), a marker for the trans-Golgi network. Yellow, the structure is positive for Golgi and protein markers. Ovals indicate cell periphery. Scale bar, $10 \mu \mathrm{m}$.

\section{Comparison of lysosomal and endosomal acidification in $A 2780$ and $A 2780$ cis cells}

Similar protein localisation patterns in A2780 cells after incubation with $\mathrm{H}^{+}$-ATPase inhibitor bafilomycin $\mathrm{A}_{1}$ and in A2780cis cells suggest that defects in lysosomal/endosomal acidification in the A2780cis cell line may be responsible for different localisation of ATP7A and ATP7B. We used FITC-dextran to compare acidification of endosomes and lysosomes in the sensitive and resistant cells. The emission intensity of FITC at $520 \mathrm{~nm}$ increases with increasing $\mathrm{pH}$ at $\lambda_{\mathrm{ex}}=485 \mathrm{~nm}$ but it is unaffected by $\mathrm{pH}$ at $\lambda_{\text {ex }}=460 \mathrm{~nm}$. Thus, the ratio of emission intensities at the two excitation wavelengths provides information about acidification of a given cellular compartment, which is independent on FITC concentration [24]. Early endosomes were labelled with FITC-dextran in cell culture medium for 5 min as described previously [23], and lysosomes were labelled with FITC-dextran for $30 \mathrm{~min}$ followed by 90 min incubation with the label-free medium following the literature procedure [24]. The ratios of FITC emission intensities after excitation at $485 \mathrm{~nm}$ and 460 $\mathrm{nm}$ are presented in Figure 5. As is clear from Figure 5, no notable difference in acidification of either endosomes or lysosomes between A2780 and A2780cis cells was observed. 
Table I: Median percentage of A2780 and A2780cis cells showing dispersed localisation of ATP7A and ATP7B.

\begin{tabular}{cccccccc}
\hline & Cell line & All cells & $P$ & Dividing cells & P (div. cells) & Non-dividing cells & $P$ (non-div. cells) \\
\hline \multirow{2}{*}{ ATP7A } & A2780 & 16.2 & & 20.0 & & 0 & 100.0 \\
\hline \multirow{2}{*}{ ATP7B } & A2780cis & 88.8 & 0.0286 & 82.6 & 0.0286 & 10 & 0.0286 \\
& A2780 & 11.1 & & 12.5 & & 0.0286 & 0.0286 \\
\hline
\end{tabular}

Median percentage values were calculated from five individual images. The significance of differences was analysed using Mann-Whitney test.

\section{Reduced lysosomal compartment in cisplatin-resistant cells}

The lysosomal dye LysoTracker ${ }^{\mathrm{TM}}$ Red DND-99 was used to compare lysosomal compartments in the A2780 and A2780cis cell lines. This lysosomal dye has been chosen for its ability to be retained in acidic organelles after formaldehyde fixation. Images of sensitive and resistant cells in which lysosomes were stained with LysoTracker ${ }^{\mathrm{TM}}$ Red and nuclei were labelled with Hoechst 33342 are presented in Figure 6A and show that cisplatin-resistant cells contain notably less acidic vesicles compared to their sensitive counterparts. This observation was confirmed by a flow cytometry study. Average fluorescence intensity of the lysosomal dye per cell was significantly lower in the resistant cell line indicating a reduced lysosomal compartment (Figure 6B).

\section{Co-localisation of ATP7A and ATP7B with a fluorescent cisplatin analogue}

In order to reveal whether ATP7A and ATP7B mediate cisplatin transport in A2780 and A2780cis cells, co-localisation experiments using a fluorescent cisplatin analogue labelled with carboxyfluorescein-diacetate (CFDA-Pt, Figure $7 \mathrm{~A}$ ) were performed. Earlier studies reported that accumulation of CFDA-Pt is lower in cisplatin-resistant cells in parallel to decreased cisplatin uptake in these cells as compared to their sensitive counterparts [33]. In addition, the cellular distribution pattern of CFDA-Pt was found to be significantly different to that of the platinumfree 1-([5-(and-6)-carboxyfluorescein diacetate]-2-(tertbutyloxycarbonyl)-1,2-ethylenediamine (CFDA-Boc, chemical structure is depicted in Figure 7A), indicating that the intracellular trafficking of CFDA-Pt is determined by the platinum moiety and not by the fluorescent label

Table 2: Median percentage of A2780 and A2780cis cells showing co-localisation of ATP7A and ATP7B with the Golgi marker.

\begin{tabular}{cccc}
\hline & A2780 & A2780cis & $P$ \\
\hline ATP7A & 92.8 & 0.0 & 0.0159 \\
ATP7B & 88.9 & 15.4 & 0.0079 \\
\hline
\end{tabular}

Median percentage values were calculated from five individual images. The significance of differences was analysed using Mann-Whitney test.
[21]. These results suggested that CFDA-Pt represents a suitable model compound for investigation of the cellular processing of cisplatin. However, antitumor activity of this complex had not been investigated, so in order to validate suitability of CFDA-Pt for our cellular system, we compared cytotoxicity of CFDA-Pt and cisplatin in A2780 and A2780cis cells. As presented in Table 4, CFDA-Pt was found to be less cytotoxic than cisplatin in both cell lines. Nevertheless, it exhibited substantial activity in A2780 cells and its activity was significantly reduced in the A2780cis cell line indicating that cisplatin-resistant cells are also resistant to CFDA-Pt ( $\sim 4$-fold resistance). These data provide evidence that CFDA-Pt can be used as a model complex in fluorescence microscopy investigations of intracellular distribution of cisplatin.

Images of A2780 and A2780cis cells incubated with CFDA-Pt and subsequently stained with antibodies to ATP7A and ATP7B are presented in Figure 7B. In the sensitive cells, both proteins showed extensive co-localisation

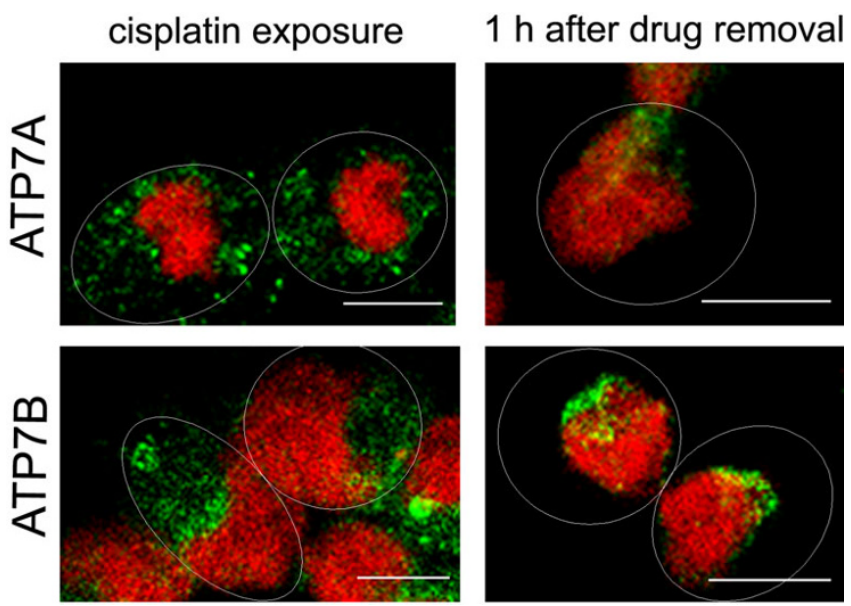

Figure 3

Localisation of ATP7A and ATP7B in A2780 cells after cisplatin exposure. Immunofluorescence localisation of ATP7A and ATP7B (both green) in A2780 cells after cisplatin exposure for $I \mathrm{~h}$ and subsequent incubation of the cells in the drug-free medium for I h. Cell nuclei were stained with propidium iodide (red). Ovals indicate cell periphery. Scale bar, $10 \mu \mathrm{m}$. 
Table 3: Median percentage of A2780 cells showing dispersed localisation of ATP7A and ATP7B after cisplatin exposure and after subsequent incubation with the drug-free medium.

\begin{tabular}{lccc}
\hline & Cisplatin exposure & I h after drug removal & $P$ \\
\hline ATP7A & 76.5 & 10.5 & 0.0043 \\
ATP7B & 70.8 & 12.2 & 0.0043 \\
\hline
\end{tabular}

Median percentage values were calculated from five individual images.

The significance of differences was analysed using Mann-Whitney test.

with CFDA-Pt. In the resistant cells, however, only ATP7A, and not ATP7B, co-localised with the fluorescent cisplatin analogue. Thus, both proteins are likely to mediate transport of CFDA-Pt in the A2780 cells but only ATP7A seems to be involved in transport of the drug in A2780cis cells. Interestingly, after the treatment with CFDA-Pt both ATP7A and ATP7B showed dispersed localisation in A2780 cells and this may indicate that CFDA-Pt induces re-localisation of the transporters to the cell periphery in the sensitive cells in the same way as cisplatin does. However, images in Figure7B do not present sufficient proof of protein re-localisation following exposure to CFDA-Pt.

\section{Discussion}

Sub cellular localisation of ATP7A and ATP7B in sensitive and resistant cells

In previous work from our laboratory, we assessed the role of copper homeostasis proteins CTR1, ATP7A and ATP7B in uptake and efflux of cisplatin in A2780 human ovarian carcinoma cell line and its cisplatin-resistant variant A2780cis cell line as well as the relevance of these transporters for tumour cell sensitivity to cisplatin [20]. Intracellular accumulation of cisplatin was found to be markedly reduced in the resistant A2780cis cell line, which is likely to result (al least in part) from the decreased expression of CTR1, a copper influx transporter believed to mediate cisplatin uptake. However, no difference in the rate of cisplatin efflux between sensitive and

ATP7A
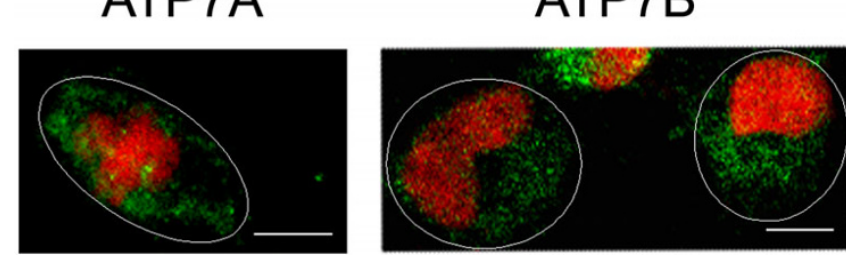

Figure 4

Effect of bafilomycin $A_{1}$ on localisation of ATP7A and ATP7B. Immunofluorescence localisation of ATP7A and ATP7B (both green) in A2780 cells treated with $200 \mathrm{nM}$ bafilomycin $A$, for $I \mathrm{~h}$. Cell nuclei were stained with propidium iodide (red). Ovals indicate cell periphery. Scale bar, 10 $\mu \mathrm{m}$.

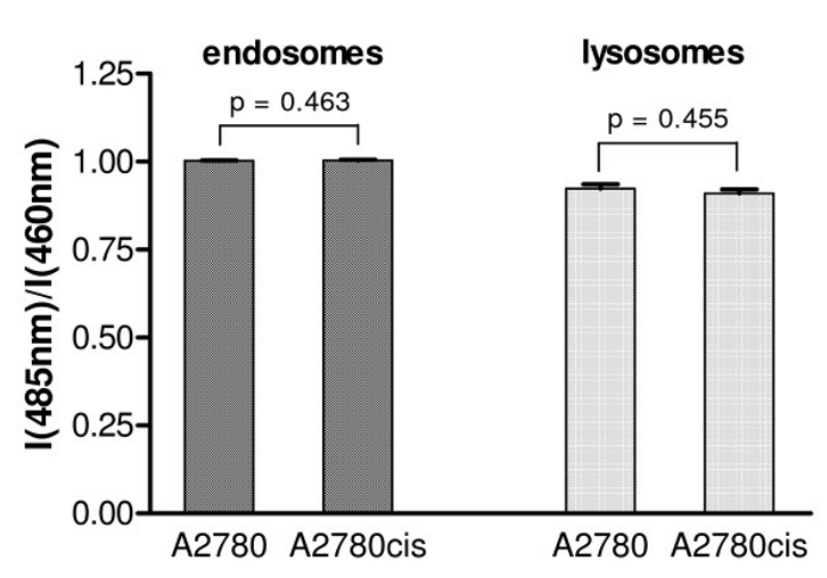

Figure 5

Comparison of lysosomal and endosomal acidification. Comparison of lysosomal and endosomal acidification in A2780 and A2780cis cells using ratios of emission intensities at $520 \mathrm{~nm}$ at the two excitation wavelengths $(485 \mathrm{~nm}$ and $460 \mathrm{~nm}$ ) after FITC-dextran labelling of endosomes and lysosomes, respectively. The results are expressed as means \pm SE of emission intensity ratios in 24 wells (endosomes) and 48 wells (lysosomes) from two independent experiments. The significance of differences was analysed using Student's $t$ test.

resistant cell line was observed, although resistant cells overexpressed the efflux transporter ATP7A. Expression of ATP7B, another transport protein previously reported to be involved in cisplatin efflux, was comparable in sensitive and resistant cells. This finding correlated well with similar efflux rates in both cell lines, however, it did not agree with the results of other groups, which linked increased expression of ATP7B to cisplatin resistance in different clonal cell lines $[10,11]$.

In an attempt to understand these contradictions, we examined the sub cellular localisation of ATP7A and ATP7B in A2780 sensitive and A2780cis resistant cells. Our results show that both proteins have different localisation patterns in A2780 and A2780cis cells. In the sensitive cells, both transporters localise in the trans-Golgi network, which is consistent with the previously reported observations in a number of other cell lines [16$19,25,26]$. However, in the resistant cells, ATP7A and ATP7B are distributed away from the trans-Golgi network to more peripherally located vesicles in the cytosol. It is not clear, to which cellular compartments these vesicles belong. It is not likely that ATP7A and ATP7B are re-localised to the lysosomal compartment given that the latter is significantly reduced in A2780cis cells. Both ATP7A and ATP7B have been previously suggested to accumulate cisplatin in vesicles of the secretory pathway $[10,18,34]$. However, the possibility that the transporters are localised 

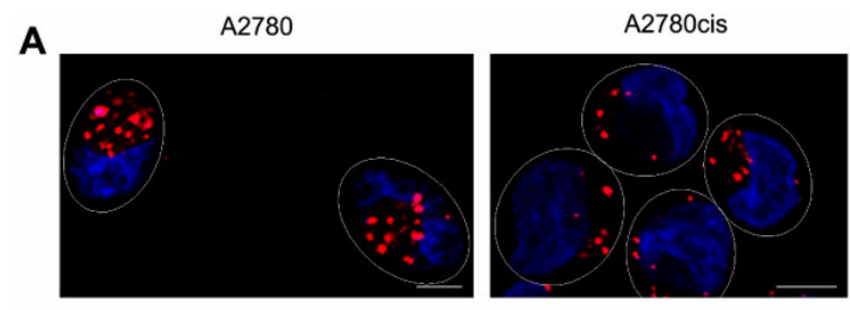

B

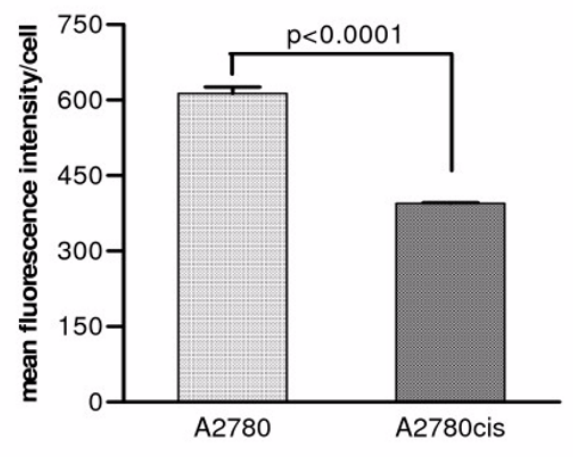

\section{Figure 6}

Lysosomal compartments in A2780 and A2780cis

cells. Comparison of the lysosomal compartments in A2780 and $A 2780$ cis cells using confocal microscopy (A) and flow cytometry (B). A. Lysosomes were labelled with LysoTracker ${ }^{\text {TM }}$ Red (red), cell nuclei were stained with Hoechst 33342 (blue). Ovals indicate cell periphery. Scale bar, $5 \mu \mathrm{m}$. B. The results represent means \pm SE of four experiments. The significance of differences was analysed using Student's $t$ test.

in vesicles of the endosomal compartment can not be ruled out. In any event, it should be pointed out that vesicular structures expressing ATP7A in the A2780cis cell line do not express ATP7B and vice versa, since ATP7A-containing vesicles co-localise with a fluorescent cisplatin analogue CFDA-Pt while vesicles containing ATP7B do not.

In A2780 cells, both transporters appear to undergo constitutive recycling between the trans-Golgi network and more peripherally located vesicles in the cytosol. Cisplatin exposure triggers rapid trafficking of ATP7A and ATP7B from the Golgi complex towards the cell periphery. The observed shift in steady-state distribution of the proteins is reversible upon removal of cisplatin from the culture medium. This system of cisplatin-regulated trafficking of ATP7A and ATP7B may indicate how cisplatin efflux by these transporters is achieved. In fact, both proteins have been reported to undergo copper-regulated trafficking between the trans-Golgi network and the plasma membrane (ATP7A) or vesicular structures at the cell periphery (ATP7B) as a way to maintain copper homeostasis [1517]. Copper-induced trafficking of ATP7A and ATP7B was also observed in A2780 cells (images not shown). How-

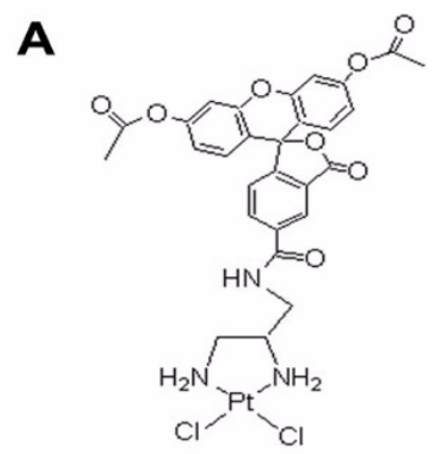

CFDA-Pt

B transporter
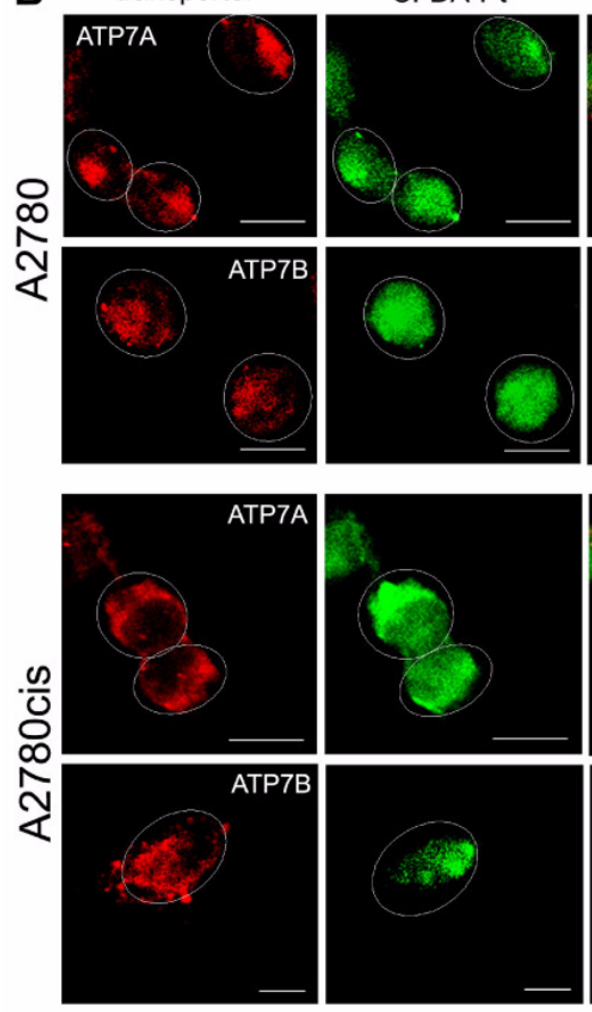

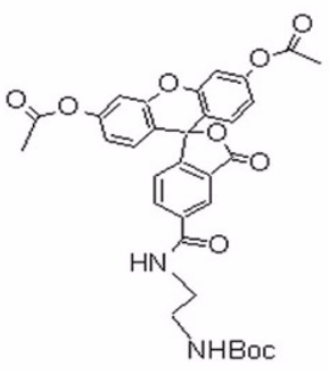

CFDA-BOC

merge

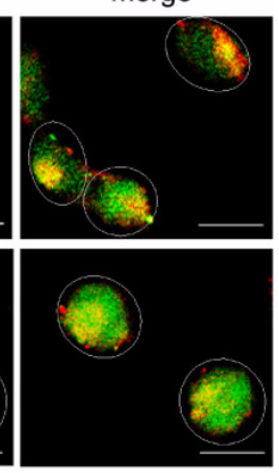

Figure 7

Co-localisation of ATP7A and ATP7B with CFDA-Pt. A. Structure of the fluorescent cisplatin analogue (CFDA-Pt) and the platinum-free fluorescein derivative (CFDA-Boc). B. Co-localisation of CFDA-Pt (green) and markers for ATP7A and ATP7B (both red) in A2780 and A2780cis cells. Yellow, the structure is positive for CFDA-Pt and protein markers. Ovals indicate cell periphery. Scale bar, $10 \mu \mathrm{m}$.

ever, in our study it was not possible to distinguish between the sites of ATP7A and ATP7B re-localisation after treatment with copper or cisplatin. Thus, our results suggest that A2780 cells utilise the same vesicular export pathway for efflux of cisplatin as they employ for export of copper. 
Table 4: Sensitivity of A2780 and A2780cis cells to cisplatin and CFDA-Pt.

\begin{tabular}{|c|c|c|c|c|c|}
\hline & \multicolumn{2}{|c|}{ A2780 } & \multicolumn{2}{|c|}{ A2780cis } & \multirow[b]{2}{*}{$P$} \\
\hline & $\mathrm{pEC}_{50}$ & $\mathrm{EC}_{50}, \mu \mathrm{M}$ & $\mathrm{pEC}_{50}$ & $\mathrm{EC}_{50}, \mu \mathrm{M}$ & \\
\hline cisplatin & $5.455 \pm 0.0941$ & 3.5 & $4.631 \pm 0.0095$ & 23.4 & 0.0001 \\
\hline CFDA-Pt & $4.445 \pm 0.1524$ & 35.9 & $3.856 \pm 0.0711$ & 139.3 & 0.0127 \\
\hline
\end{tabular}

Sensitivity of A2780 and A2780cis cells to cisplatin and CFDA-Pt was assessed using an MTT-based assay. The pEC 50 values are means \pm SE of four experiments. The significance of differences was analysed using Student's $t$ test.

\section{Possible causes of altered localisation of transporters in resistant cells}

Continuous recycling of the copper efflux transporters between the Golgi complex and peripherally located vesicles in the cytosol appears to be blocked in the cisplatinresistant A2780cis cell line. As a result, the proteins are sequestrated in vesicular structures in the cytosol. Looking for possible cellular alterations, which may account for different localisation of ATP7A and ATP7B in the resistant cells, we compared acidification of the lysosomal and endosomal compartment in A2780 and A2780cis cell lines. Vesicular trafficking and protein turnover are very sensitive to even small changes in organelle $\mathrm{pH}$ and we hypothesised that altered localisation of ATP7A and ATP7B in the resistant cells may be a consequence of acidification defects of the lysosomal and/or endosomal compartment. Some cisplatin-resistant cell lines have previously been reported to have less acidic lysosomes than their sensitive counterparts [35-38]. However, no notable differences in acidification of either lysosomes or endosomes between sensitive and resistant cells were observed in our case.

Interestingly, the cisplatin-resistant A2780cis cells were found to have significantly less lysosomes than the sensitive A2780 cells. Lysosomes play an important role in the vesicular trafficking [39]. They represent a terminal degradative compartment of the endocytic pathway. Lysosomes receive their enzymes from the trans-Golgi network mainly via late endosomes (also called multivesicular bodies), which also sort internalised proteins for recycling or degradation in lysosomes [40]. Unfortunately, the mechanism of delivery of endocytosed material from endosomes to lysosomes is not well elucidated [41]. Several possible pathways have been proposed [41] including maturation of late endosomes into lysosomes, vesicular transport from late endosomes to lysosomes, so-called 'kiss-and-run' (a cycle of transient contacts between endosomes and lysosomes, which allow exchange of the material between them, followed by dissociation) and direct fusion to form a hybrid organelle, which contains both late endosome and lysosome components and where the endocytic cargo is either recycled or digested. Any of these mechanisms represent a sequence of highly regulated intracellular events and even small alterations may lead to the failure of the whole pathway to function properly. A reduction of the lysosomal compartment in the cisplatinresistant cell line may indicate decreased protein trafficking from late endosomes to lysosomes due to mis-sorting of proteins in late endosomes and may reflect a general defect in intracellular protein trafficking, which may prevent constitutive recycling of ATP7A and ATP7B and eventually lead to sequestration of these transporters in the vesicular structures of resistant cells. Our results confirm findings of other groups, that the lysosomal compartment in cells with acquired resistance to cisplatin features major abnormalities, which eventually results in changes in protein processing $[35-37,42]$. We suggest that the reduced lysosomal compartment may reflect defects in protein recycling, which may in turn be responsible for altered localisation of the efflux transporters ATP7A and ATP7B in the A2780cis resistant cell line.

\section{Consequences of altered localisation of the transporters in resistant cells}

In order to investigate possible consequences of altered localisation of ATP7A and ATP7B, co-localisation experiments using a fluorescent cisplatin analogue modified with carboxyfluorescein-diacetate (CFDA-Pt) were carried out. Some reports in the literature $[6,43]$ argue that CFDA$\mathrm{Pt}$ is not likely to behave similarly to cisplatin inside the cell because a large lipophilic fluorophore would significantly change the pharmacokinetic properties of the complex. However, there are several lines of evidence that CFDA-Pt represents a suitable model complex for investigation of intracellular transport of cisplatin. Firstly, the cellular distribution of CFDA-Pt was found different from that of the platinum-free fluorophore CFDA-Boc $[21,33]$. Secondly, cellular accumulation of CFDA-Pt in cisplatinresistant $\mathrm{U} 2-\mathrm{OS} / \mathrm{Pt}$ osteosarcoma cells was found to be reduced compared to its accumulation in sensitive U2-OS cells [33], which is in agreement with decreased cisplatin accumulation in the U2-OS/Pt cell line [33,44]. Finally, the results of the cytotoxicity tests presented here show that CFDA-Pt exhibits substantial activity in the A2780 cell line and cross-resistance with cisplatin in the A2780cis cell line. Taken together, these findings strongly suggest that modification of cisplatin with carboxyfluores- 
cein-diacetate does not alter the pharmacological properties of the complex, which are important for the cisplatinresistant phenotype.

Co-localisation experiments showed that CFDA-Pt is associated with ATP7A and ATP7B in cisplatin-sensitive A2780 cells. Both transporters have been previously reported to co-localise with a fluorescein-labelled cisplatin analogue in vesicles of the secretory pathway $[18,34]$. Based on the data obtained using different transfected cell lines it has been suggested that ATP7B mediates cisplatin efflux, whereas ATP7A functions to sequester the drug in the vesicular compartment [12]. On the contrary, in the A2780 cell line both proteins appear to be involved in cisplatin efflux, since cisplatin triggers trafficking of both transporters away from the trans-Golgi network to vesicular compartments on the cell periphery. It should, however, be pointed out that the cell lines transfected with ATP7A and ATP7B exhibited biologically relevant degree of cisplatin resistance and cannot, therefore, be directly compared with cisplatin-sensitive cell lines. Otherwise, since cisplatin serves as a substrate for both ATP7A and $\mathrm{ATP} 7 \mathrm{~B}$, it is also possible that the presence of considerable amounts of both transporters in the cell in some way influences their function, which is not the case in a clonal cell line engineered to overexpress one of the proteins.

In the cisplatin-resistant cell line, ATP7A was found to colocalise with CFDA-Pt, and only a negligible degree of colocalisation between the complex and ATP7B was observed. Therefore, in spite of altered localisation ATP7A appears to mediate either efflux or sequestration of cisplatin in the A2780cis cells. Sequestration is more likely to take place given higher expression of the transporter in the resistant cell line and nonetheless similar efflux rate in both cell lines [20]. It is also in agreement with previously reported data, which suggested that ATP7A regulates cell sensitivity to cisplatin by sequestrating it in the vesicular compartment $[11,12]$. In contrast, re-localisation of ATP7B away from the trans-Golgi network to peripherally located vesicles appears to prevent cisplatin binding to this protein and does not allow ATP7B to perform cisplatin efflux in the resistant cells. As a result, the drug becomes sequestrated intracellularly, possibly in ATP7Aexpressing vesicles.

In the sensitive A2780 cells, both ATP7A and ATP7B are likely to mediate cisplatin transport. Due to altered localisation of the proteins in the resistant A2780cis cell line, ATP7A appears to dominate over ATP7B in cisplatin binding and to determine the intracellular fate of the drug. This is in agreement with increased expression of ATP7A and unchanged expression levels of ATP7B in resistant cells compared to their sensitive counterparts [20]. Given peripheral localisation of ATP7A in A2780cis cells, cispla- tin may encounter this protein directly after it enters the cell, which may subsequently result in cisplatin sequestration in ATP7A-expressing vesicles and therefore prevent its binding to nuclear DNA. This is supported by the previous findings that cellular accumulation of cisplatin is 2.5 times lower in the A2780cis cell line compared to the A2780 cell line, while DNA platination is, on average, reduced 5.4-fold [20]. It should be noted, however, that other factors such as increased glutathione levels in the A2780cis cell line (Zisowsky et al., unpublished data) are also involved in regulating intracellular transport of cisplatin and cisplatin sensitivity of A2780cis cells.

\section{Conclusion}

Taken together, our results suggest that changes in sub cellular localisation of copper efflux transporters may account for acquired resistance to cisplatin. Altered localisation of ATP7A and ATP7B in A2780cis cells is likely to result from a general defect in intracellular protein recycling, which may be related to the reduced lysosomal compartment in this cell line. Earlier studies have indicated that accumulation of cisplatin in the secretory pathway may require lysosomal function. Abnormalities in structure and function of the lysosomal compartment may promote sequestration of cisplatin away from its pharmacological target, nuclear DNA, due to incorrect localisation of transport proteins.

The results of the present study further indicate that sub cellular localisation of transport proteins can serve as a marker for detection of clinically relevant cisplatin resistance. Using modern imaging technology it should be possible to identify resistant tumours at an early stage of chemotherapy and to adjust the treatment accordingly. In order to validate this approach, further studies should focus on the transporter localisation in tumour cells isolated from different patients and correlation of protein localisation patterns with clinical response to cisplatin chemotherapy. The results may contribute to the development of new individualised therapeutic strategies in cisplatin treatment of ovarian carcinoma.

\section{Competing interests}

The authors declare that they have no competing interests.

\section{Authors' contributions}

CHW carried out cytotoxicity tests and some immunohistochemical staining experiments, IB performed some immunohistochemical staining experiments, GVK designed the study, performed the rest of the experiments and wrote the manuscript. UJ participated in the study design and data interpretation, and contributed to drafting the paper. JR participated in discussion of the results. All authors critically revised the manuscript, read and approved its final version. 


\section{Acknowledgements}

The financial support of the Alexander von Humboldt Foundation (research fellowship for Dr. Ganna V. Kalayda) is kindly acknowledged. The authors wish to thank Prof. Michael Hoch and his research group, in particular Dr. Bernhard Fuß and Dr. Matthias Behr (LIMES Institute, University of Bonn), for the opportunity to use the Leica TCS SP2 confocal system and their kind assistance. The authors are grateful to Dr. Thomas Quast (LIMES Institute, University of Bonn) for his assistance in using the Olympus U-TBI90 confocal microscope. The authors wish to thank Dr. Geoff Cooper (Leiden Institute of Chemistry, Leiden University) for correcting English of the manuscript. The authors are also grateful to Johnson\&Matthey for their generous loan of $\mathrm{K}_{2} \mathrm{PtCl}_{4}$.

\section{References}

I. Kelland L: The resurgence of platinum-based cancer chemotherapy. Nat Rev Cancer 2007, 7:573-584.

2. Siddik ZH: Cisplatin: mode of cytotoxic action and molecular basis of resistance. Oncogene 2003, 22:7265-7279.

3. Perez RP: Cellular and molecular determinants of cisplatin resistance. Eur J Cancer 1998, 34:1535-1542.

4. Gately DP, Howell SB: Cellular accumulation of the anticancer agent cisplatin - a review. Br J Cancer 1993, 67: II71-1 176.

5. Stewart DJ: Mechanisms of resistance to cisplatin and carboplatin. Crit Rev Oncol Hematol 2007, 63:|2-3|.

6. Hall MD, Okabe M, Shen DW, Liang XJ, Gottesman MM: The role of cellular accumulation in determining sensitivity to platinum-based chemotherapy. Annu Rev Pharmacol Toxicol 2008, 48:495-535.

7. Katano K, Kondo A, Safaei R, Holzer A, Samimi G, Mishima M, Kuo YM, Rochdi M, Howell SB: Acquisition of resistance to cisplatin is accompanied by changes in the cellular pharmacology of copper. Cancer Res 2002, 62:6559-6565.

8. Safaei R, Holzer AK, Katano K, Samimi G, Howell SB: The role of copper transporters in the development of resistance to $\mathbf{P t}$ drugs. J Inorg Biochem 2004, 98:1607-1613.

9. Safaei R, Katano K, Samimi G, Naerdemann W, Stevenson JL, Rochdi $M$, Howell SB: Cross-resistance to cisplatin in cells with acquired resistance to copper. Cancer Chemother Pharmacol 2004, 53:239-246.

10. Samimi G, Katano K, Holzer AK, Safaei R, Howell SB: Modulation of the cellular pharmacology of cisplatin and its analogs by the copper exporters ATP7A and ATP7B. Mol Pharmacol 2004, 66:25-32.

II. Safaei R, Howell SB: Copper transporters regulate the cellular pharmacology and sensitivity to Pt drugs. Crit Rev Oncol Hematol 2005, 53:13-23.

12. Safaei R: Role of copper transporters in the uptake and efflux of platinum containing drugs. Cancer Lett 2006, 234:34-39.

13. Komatsu M, Sumizawa T, Mutoh M, Chen ZS, Terada K, Furukawa T, Yang XL, Gao H, Miura N, Sugiyama T, Akiyama S: Copper-transporting P-type adenosine triphosphatase (ATP7B) is associated with cisplatin resistance. Cancer Res 2000, 60:1312-1316.

14. Samimi G, Varki NM, Wilczynski S, Safaei R, Alberts DS, Howell SB: Increase in expression of the copper transporter ATP7A during platinum drug-based treatment is associated with poor survival in ovarian cancer patients. Clin Cancer Res 2003, 9:5853-5859.

15. Pena MM, Lee J, Thiele DJ: A delicate balance: homeostatic control of copper uptake and distribution. I Nutr 1999, I 29:125I-1260.

16. Petris MJ, Mercer JFB, Culvenor JG, Lockhart P, Gleeson PA, Camakaris J: Ligand-regulated transport of the Menkes copper P-type ATPase efflux pump from the Golgi apparatus to the plasma membrane: A novel mechanism of regulated trafficking. EMBO J 1996, I 5:6084-6095.

17. Roelofsen H, Wolters H, van Luyn MJA, Miura N, Kuipers F, Vonk RJ: Copper-induced apical trafficking of ATP7B in polarized hepatoma cells provides a mechanism for biliary copper excretion. Gastroenterology 2000, I 1 9:782-793.

18. Katano K, Safaei R, Samimi G, Holzer A, Tomioka M, Goodman M, Howell SB: Confocal microscopic analysis of the interaction between cisplatin and the copper transporter ATP7B in human ovarian carcinoma cells. Clin Cancer Res 2004, 10:4578-4588.

19. Samimi G, Safaei R, Katano K, Holzer AK, Rochdi M, Tomioka M, Goodman M, Howell SB: Increased expression of the copper efflux transporter ATP7A mediates resistance to cisplatin, carboplatin, and oxaliplatin in ovarian cancer cells. Clin Cancer Res 2004, 10:466 I-4669.

20. Zisowsky J, Koegel S, Leyers S, Devarakonda K, Kassack MU, Osmak $M$, Jaehde U: Relevance of drug uptake and efflux for cisplatin sensitivity of tumor cells. Biochem Pharmacol 2007, 73:298-307.

21. Molenaar C, Teuben JM, Heetebrij RJ, Tanke HJ, Reedijk J: New insights in the cellular processing of platinum antitumor compounds, using fluorophore-labeled platinum complexes and digital fluorescence microscopy. J Biol Inorg Chem 2000, 5:655-665.

22. Alley MC, Scudiero DA, Monks A, Hursey ML, Czerwinski MJ, Fine DL, Abbott BJ, Mayo JG, Shoemaker RH, Boyd MR: Feasibility of drug screening with panels of human tumor cell lines using a microculture tetrazolium assay. Cancer Res 1988, 48:589-601.

23. Fuchs R, Schmid S, Mellman I: A possible role for $\mathbf{N a +}, \mathbf{K}+-A T P a s e$ in regulating ATP-dependent endosome acidification. Proc Natl Acad Sci U S A 1989, 86:539-543.

24. Altan N, Chen Y, Schindler M, Simon SM: Defective acidification in human breast tumor cells and implications for chemotherapy. J Exp Med 1998, 187:1583-1598.

25. Petris MJ, Voskoboinik I, Cater M, Smith K, Kim BE, Llanos RM, Strausak D, Camakaris J, Mercer JF: Copper-regulated trafficking of the Menkes disease copper ATPase is associated with formation of a phosphorylated catalytic intermediate. J Biol Chem 2002, 277:46736-46742.

26. Schaefer M, Roelofsen H, Wolters H, Hofmann WJ, Muller M, Kuipers F, Stremmel W, Vonk RJ: Localization of the Wilson's disease protein in human liver. Gastroenterology 1999, I 17:1380-1385.

27. Bos K, Wraight C, Stanley KK: TGN38 is maintained in the trans-Golgi network by a tyrosine-containing motif in the cytoplasmic domain. EMBO J 1993, I 2:2219-2228.

28. Molloy SS, Thomas L, VanSlyke JK, Stenberg PE, Thomas G: Intracellular trafficking and activation of the furin proprotein convertase: localization to the TGN and recycling from the cell surface. $E M B O J$ 1994, I 3:18-33.

29. Chapman RE, Munro S: Retrieval of TGN proteins from the cell surface requires endosomal acidification. EMBO J 1994, 13:2305-2312.

30. Reaves B, Banting G: Vacuolar ATPase inactivation blocks recycling to the trans-Golgi network from the plasma membrane. FEBS Lett 1994, 345:61-66.

31. Gruenberg J, Maxfield FR: Membrane transport in the endocytic pathway. Curr Opin Cell Biol 1995, 7:552-563.

32. Tapper H, Sundler R: Bafilomycin AI inhibits lysosomal, phagosomal, and plasma membrane $H(+)$-ATPase and induces lysosomal enzyme secretion in macrophages. J Cell Physiol 1995, 163:137-144.

33. Kalayda GV, Zhang G, Abraham T, Tanke HJ, Reedijk J: Application of fluorescence microscopy for investigation of cellular distribution of dinuclear platinum anticancer drugs. J Med Chem 2005, 48:5191-5202.

34. Safaei R, Katano K, Larson BJ, Samimi G, Holzer AK, Naerdemann W, Tomioka M, Goodman M, Howell SB: Intracellular localization and trafficking of fluorescein-labeled cisplatin in human ovarian carcinoma cells. Clin Cancer Res 2005, I I:756-767.

35. Chauhan SS, Liang XJ, Su AW, Pai-Panandiker A, Shen DW, Hanover JA, Gottesman MM: Reduced endocytosis and altered lysosome function in cisplatin-resistant cell lines. Br J Cancer 2003, 88: I327-I334.

36. Liang XJ, Shen DW, Garfield S, Gottesman MM: Mislocalization of membrane proteins associated with multidrug resistance in cisplatin-resistant cancer cell lines. Cancer Res 2003, 63:5909-5916.

37. Liang XJ, Shen DW, Gottesman MM: A pleiotropic defect reducing drug accumulation in cisplatin-resistant cells. J Inorg Biochem 2004, 98:1599-1606.

38. Kalayda GV, Jansen BAJ, Wielaard P, Tanke HJ, Reedijk J: Dinuclear platinum anticancer complexes with fluorescent $N, N$ 'bis(aminoalkyl)-I,4-diaminoanthra-quinones: cellular processing in two cisplatin resistant cell lines reflects the dif- 
ferences in their resistance profiles. J Biol Inorg Chem 2005, 10:305.

39. Schwartz AL: Cell biology of intracellular protein trafficking. Annu Rev Immunol 1990, 8: 195-229.

40. Katzmann DJ, Babst M, Emr SD: Ubiquitin-dependent sorting into the multivesicular body pathway requires the function of a conserved endosomal protein sorting complex, ESCRTI. Cell 200I, 106:145-155.

4I. Luzio JP, Pryor PR, Bright NA: Lysosomes: fusion and function. Nat Rev Mol Cell Biol 2007, 8:622-632.

42. Safaei R, Larson BJ, Cheng TC, Gibson MA, Otani S, Naerdemann W, Howell SB: Abnormal lysosomal trafficking and enhanced exosomal export of cisplatin in drug-resistant human ovarian carcinoma cells. Mol Cancer Ther 2005, 4: 1595-1604.

43. Hall MD, Dillon CT, Zhang M, Beale P, Cai Z, Lai B, Stampfl APJ, Hambley TW: The cellular distribution and oxidation state of platinum (II) and platinum (IV) antitumor complexes in cancer cells. J Biol Inorg Chem 2003, 8:726-732.

44. Perego P, Caserini C, Gatti L, Carenini N, Romanelli S, Supino R, Colangelo D, Viano I, Leone R, Spinelli S, Pezzoni G, Manzotti C, Farrell $\mathrm{N}$, Zunino F: A novel trinuclear platinum complex overcomes cisplatin resistance in an osteosarcoma cell system. Mol Pharmacol 1999, 55:528-534.

\section{Pre-publication history}

The pre-publication history for this paper can be accessed here:

http://www.biomedcentral.com/1471-2407/8/175/pre pub

Publish with Biomed Central and every scientist can read your work free of charge

"BioMed Central will be the most significant development for disseminating the results of biomedical research in our lifetime. "

Sir Paul Nurse, Cancer Research UK

Your research papers will be:

- available free of charge to the entire biomedical community

- peer reviewed and published immediately upon acceptance

- cited in PubMed and archived on PubMed Central

- yours - you keep the copyright

Submit your manuscript here:

http://www.biomedcentral.com/info/publishing_adv.asp
BioMedcentral 